\title{
Assessment of Basic Knowledge, Attitude and Practice of Community on Rabies and Retrospective Survey in and around Ambo Town, West Shoa Zone of Ethiopia
}

\author{
Tamiru Dabuma ${ }^{1}$, Tadele Kabeta ${ }^{1}$ and Hylemariam Mihiretie Mengist ${ }^{2 *}$ \\ ${ }^{1}$ Department of Veterinary Medicine, Wollega University College of Medical and Health Science, Nekemte, Ethiopia \\ ${ }^{2}$ Department of Medical Laboratory Sciences, Wollega University College of Medical and Health Science, Nekemte, Ethiopia
}

\begin{abstract}
Background: Rabies is acute fatal encephalitis that affects all mammals and is a worldwide zoonotic disease caused by rabies virus. Knowledge, Attitudes and Practice (KAP) of the community on rabies is vital to prevent the neglected deadly disease. The aim of the study was to assess the KAP of the community on rabies in and around Ambo town, Ethiopia.

Methods: A cross sectional and retrospective studies were conducted from November 2015-April 2016 in and around Ambo town to assess knowledge, attitude and practice (KAP) of community on rabies; and to know a oneyear status of human rabies suspected case in Ambo hospital. The study participants were enrolled consecutively, and data was collected using questionnaires. Data was cleaned, coded and entered for analysis by SPSS version 20 software. KAP were defined based on mean scores.

Results: The questioners survey indicated that the communities had poor knowledge, good attitude and good practice with $(46.1 \%),(50.5 \%)$ and $(63.5 \%)$, respectively. Hence the overall KAP scores were good $(53.4 \%)$ implying that the communities had good awareness about rabies. There was no statically significant association between sex and age of respondents with knowledge, attitude and practice scores $(p>0.05)$. There was statistically significant association between educational level with knowledge and attitude scores $(p<0.05)$. The retrospective review showed that the majority of suspected cases were males $(52.4 \%)$. Almost all suspected cases were bitten by dog $(94.2 \%)$ followed by human bites (3.8\%). Majority of suspected case were recorded in autumn and winter (35.6\%).

Conclusion: This study showed that there was terrestrial rabies (human, canine, sylvatic) that leads to human rabies suspected case and awareness of respondents on rabies were good although poor about wound management for bitten individuals in the study areas. Further public awareness creation is still essential on multidimensional impacts of rabies, responsible pet ownership, managements of bitten animals, first aid treatment and on the use of traditional remedy.
\end{abstract}

Keywords: Ambo town; KAP; Rabies; Ethiopia

\section{Introduction}

Human health is highly linked to animal health. The link is close in developing countries. More than one-half of the 1700 agents known to infect humans were reported to have association with animals [1]. Rabies is acute fatal encephalitis that affects all mammals and is a worldwide zoonotic disease caused by rabies virus [2]. The disease is one of the longest known infectious diseases in human history [3].

Rabies is a prime example of a neglected tropical disease that mostly affects poor communities, children and elderly people suffering from inequitable health care. In Africa, the highest recorded human death due to the disease for the year 1998 was reported from Ethiopia. The magnitude of the problem is higher in big cities like Addis Ababa linked with the presence of large population of stray dogs and associated factors $[4,5]$.

Rabies was reported to be one of the public health concerns that need formulation of intervention strategy in Ethiopia. Information on occurrence of the rabies and associated risk factors in a given locality/ community is crucial to plan and implement appropriate control the measures. Many studies have been carried out to assess the knowledge, attitudes and practices (KAP) of communities or physicians regarding rabies throughout the world.

KAP surveys of community have been undertaken in Ethiopia mainly in and around urban areas. However, a community based KAP study with their associated risk factors haven't been carried out in and around Ambo town, yet. Hence, questionnaire survey of communities in and around Ambo town and retrospective and survey based study have been carried out in the Ambo town.

\section{Materials and Methods}

\section{Study setting and context}

A community based cross sectional study and retrospective record review was conducted in Ambo, capital city of West Showa zone in Oromia Regional State, Ethiopia, from November 2015-April 2016. The town is located at $114 \mathrm{~km}$ west of Addis Ababa and has altitude of 2,185 meter above sea level (masl). The geographical location of Ambo town is

*Corresponding authors: Hylemariam Mihiretie Mengist, Department of Medical Laboratory Sciences, Wollega University College of Medical and Health Science, Nekemte, P.O Box 395, Ethiopia, Tel: 251576617 981; E-mail: hylemariam@gmail.com

Received July 26, 2017; Accepted November 07, 2017; Published November 10, 2017

Citation: Dabuma T, Kabeta T, Mengist HM (2017) Assessment of Basic Knowledge, Attitude and Practice of Community on Rabies and Retrospective Survey in and around Ambo Town, West Shoa Zone of Ethiopia. J Med Microb Diagn 6: 263. doi:10.4172/2161-0703.1000263

Copyright: @ 2017 Dabuma T, et al. This is an open-access article distributed under the terms of the Creative Commons Attribution License, which permits unrestricted use, distribution, and reproduction in any medium, provided the original author and source are credited. 
approximately between $8^{\circ} 56^{\prime} 30^{\prime \prime} \mathrm{N}$ and $8^{\circ} 59^{\prime} 30^{\prime \prime} \mathrm{N}$ latitude and between $37^{\circ} 47^{\prime} 30^{\prime \prime} \mathrm{E}$ and $37^{\circ} 55^{\prime} 15^{\prime \prime} \mathrm{E}$ longitude. The mean annual temperature, the annual maximum and the annual minimum temperatures of the area were about $18.8,26$ and $10.76^{\circ} \mathrm{C}$, respectively. The mean annual rainfall is about $1,143 \mathrm{~mm}$ and the highest rainfall occurs from June to September. Human population of the town was 67,514 , out of which $34,276(50.8 \%)$ were males and 33,238 (49.2\%) were females [6]. There are approximately 112,236 heads of cattle, 24,966 heads of sheep and 16,399 heads of goats in Ambo district [7].

\section{Sample size and sampling technique}

All data available in 2015 was used for the retrospective study and sample size for KAP was calculated using a single population proportion formula considering $\mathrm{P}=50 \%$ Thus, the sample size was calculated according to previous study [8], using $95 \%$ confidence interval and 0.05 absolute precision.

$$
\mathrm{n}=1.96^{2} \times \mathrm{P}_{\exp }\left(1-\mathrm{P}_{\exp }\right) / \mathrm{d}^{2} \text { where, }
$$

$\mathrm{n}=$ Required sample size,

$\mathrm{P}=$ Expected proportion of population knowing about Rabies is $50 \%$,

\section{$\mathrm{d}=$ Desired absolute precision $(0.05)$}

Hence, 386 target populations were selected from the total sample size of 406 with $5 \%$ non-response rate. The study participants were enrolled consecutively.

\section{Data Collection}

Retrospective data was collected from registered book of admitted individuals for the rabies case in 2015. For assessment of KAP of the communities open and close ended questionnaire survey was developed in English for the target population and translated to local language (Afan Oromo). Face to face interview was used to collect data after pretest was performed on $5 \%$ of the study population.

\begin{tabular}{|c|c|c|}
\hline Variables & $\begin{array}{l}\text { Number of case } \\
\text { recorded }\end{array}$ & Percentage (\%) \\
\hline \multicolumn{3}{|c|}{ Residence } \\
\hline $\begin{array}{c}\text { Rural (Outside of Ambo } \\
\text { town) }\end{array}$ & 113 & 54.3 \\
\hline Urban (From Ambo town) & 95 & 45.7 \\
\hline \multicolumn{3}{|c|}{ Sex } \\
\hline Male & 109 & 52.4 \\
\hline Female & 99 & 47.6 \\
\hline \multicolumn{3}{|c|}{ Age } \\
\hline Children (2-15) & 102 & 49.0 \\
\hline Young (16-29) & 71 & 34.1 \\
\hline Adult (30-43) & 28 & 13.5 \\
\hline Old (44-70) & 7 & 3.4 \\
\hline \multicolumn{3}{|c|}{ Source of exposure } \\
\hline Dog & 196 & 94.2 \\
\hline $\begin{array}{l}\text { Animals (cats, equines, } \\
\text { bovines) }\end{array}$ & 2 & 1.0 \\
\hline Human & 8 & 3.8 \\
\hline Fox & 2 & 1.0 \\
\hline \multicolumn{3}{|c|}{ Season } \\
\hline Summer & 49 & 23.6 \\
\hline Autumn & 74 & 35.6 \\
\hline Winter & 74 & 35.6 \\
\hline Spring & 11 & 5.3 \\
\hline
\end{tabular}

Table 1: Retrospective study on occurrence of rabies suspected case from Ambo town for 2015 .

\section{Data management and analysis}

The information (raw data) that was gathered through questionnaire survey and retrospective record were coded and entered in to a Microsoft excel 2007 spread sheet computer program. Before the analysis of the coded data it was filtered. Descriptive statistics (percentage and frequency distribution) were utilized to summarize the data using Software program for Social Science (SPSS) version 20 to calculate the frequency of the respondents. P-Value was used to assess if there was association between risk factors (age, sex and education) and KAP scores. In all cases, a 95\% CI was employed to estimate sample results to the target population in the study area. Values of $\mathrm{P}<0.05$ were considered statistically significant. Knowledge, attitude and practice were classified as "poor" for those scored below mean and "good" for those scored above the mean.

\section{Ethical considerations}

The study protocol was ethically reviewed and approved by the Departmental Research and Ethical Committee of Wollega University, School of Veterinary Medicine. Then the University sent a letter informing the Hospital administrators about the study and hence permission obtained from Health centers. Data were collected after obtaining written consent and confidentiality was maintained throughout the study by using codes.

\section{Inclusion and exclusion criteria}

Randomly selected group of respondents were included in the questioner survey. Children less than 15 years, who cannot well express their ideas was excluded from interview. Exposed cases had complete record on rabies registration book in Ambo hospital was included while data which incompletely information was excluded in retrospective survey.

\section{Results}

\section{Retrospective study on rabies in Ambo town}

A total of 209 rabies exposed patients were recorded from oneyear (2015) rabies registration book during the study periods. The retrospective review showed that the majority of suspected cases were males (52.4\%). Almost all suspected cases were bitten by dog (94.2\%) followed by human bites (3.8\%). Majority of suspected case were recorded in autumn and winter (35.6\%) in Table 1.

\section{Socio-demographic characteristics}

A total of 386 individuals participated in the study. The highest $(42.7 \%)$ of participants were within the age range of 31-50 years. The majority of respondent were Females $(52.6 \%)$. The majority of the respondents have informal education (33.9\%) and their occupation was business man (35.2\%) (Table 2).

\section{Knowledge, attitude and practice of communities on rabies}

From the interviewed participants, $32.4 \%$ knew that heredity is the source of rabies. Majority (96.1\%) responded that dog is the common source and $37 \%$ agreed that cats can transmit the disease like dogs. About $41 \%$ responded that rabid animals are the major means of rabies transmission. Majority (95.9\%) of the respondent indicated that rabies case occurred in winter season. Only $9.8 \%$ of the respondents were aware of the presence of post exposure prophylaxis (PEP). A little more than the half $(52.6 \%) \mathrm{knew}$ as it is possible to manage rabies by Holy water. Around $36.5 \%$ respondents accepted that there was specific medical drug therapy in the Health centre (Table 3). 
Citation: Dabuma T, Kabeta T, Mengist HM (2017) Assessment of Basic Knowledge, Attitude and Practice of Community on Rabies and Retrospective Survey in and around Ambo Town, West Shoa Zone of Ethiopia. J Med Microb Diagn 6: 263. doi:10.4172/2161-0703.1000263

Page 3 of 5

Among the attitude related variables, large population of stray dogs (59.6\%), No curability of rabies after development of symptoms (52.1\%), and insufficiency of responsible veterinarians $(51.6 \%)$, religious taboo

\begin{tabular}{|c|c|c|}
\hline Variables & Number of respondents & Percentage (\%) \\
\hline \multicolumn{3}{|c|}{ Residence } \\
\hline Urban & 193 & 50 \\
\hline Per urban & 73 & 18.9 \\
\hline Rural & 120 & 31.1 \\
\hline & Age \\
\hline $15-30$ & 122 & 31.6 \\
\hline $31-50$ & 165 & 42.7 \\
\hline$>50$ & 99 & 25.6 \\
\hline & Sex & 47.4 \\
\hline Male & 183 & 52.6 \\
\hline Female & 203 & 33.9 \\
\hline & Education & 25.1 \\
\hline Informal school & 131 & 20.7 \\
\hline Primary school & 97 & 20.2 \\
\hline High/Prep. School & 80 & \\
\hline Higher education & 78 & 33.4 \\
\hline & Occupation & 35.2 \\
\hline Housewife & 129 & 21.2 \\
\hline Businessman & 136 & 3910.1 \\
\hline Farmer & 82 & \\
\hline Employee & 39 & \\
\hline
\end{tabular}

Table 2: Socio-demographic characteristics of respondents in and around Ambo town, 2016.

\begin{tabular}{|c|c|c|}
\hline Knowledge related variable & Number of respondents & Percentage (\%) \\
\hline \multicolumn{3}{|c|}{ What is the cause of rabies? } \\
\hline Spiritual & 35 & 9.1 \\
\hline Germ & 91 & 23.6 \\
\hline Heredity & 125 & 32.4 \\
\hline Other & 146 & 37.8 \\
\hline I don't know & 118 & 30.6 \\
\hline \multicolumn{3}{|c|}{ In which season rabies occurred more? } \\
\hline Autumn & 98 & 25.4 \\
\hline Spring & 133 & 34.5 \\
\hline Summer & 97 & 25.1 \\
\hline Winter & 370 & 95.91 \\
\hline Unknown & 114 & 29.5 \\
\hline \multicolumn{3}{|c|}{ How rabies is transmitted? } \\
\hline Bite by any rabid animal & 157 & 40.7 \\
\hline $\begin{array}{l}\text { Consumption of rabid animal } \\
\text { meat }\end{array}$ & 115 & 29.8 \\
\hline Inhalation & 67 & 17.4 \\
\hline Other & 143 & 37 \\
\hline I don't know & 237 & 61.4 \\
\hline \multicolumn{3}{|c|}{ Which animals transmit rabies? } \\
\hline Dogs & 371 & 96.1 \\
\hline Dogs and Cats & 143 & 37 \\
\hline Wild carnivores & 77 & 19.9 \\
\hline \multicolumn{3}{|c|}{ How rabies suspected bite is managed? } \\
\hline Herbal remedies & 141 & 36.5 \\
\hline Specific drugs & 147 & 38.1 \\
\hline $\begin{array}{l}\text { Post exposure prophylaxis } \\
\text { (PEP) }\end{array}$ & 38 & 9.8 \\
\hline Holy water & 203 & 52.6 \\
\hline I don't know & 118 & 30.6 \\
\hline
\end{tabular}

Table 3: Knowledge of respondents on rabies in and around Ambo town, 2016.

\begin{tabular}{|c|c|c|}
\hline Attitude related variables & Number of respondents & Percentage (\%) \\
\hline \multicolumn{3}{|c|}{ Constraints to prevent and control rabies } \\
\hline Insufficient budget & 55 & 14.2 \\
\hline $\begin{array}{l}\text { Insufficiency of responsible } \\
\text { veterinarians }\end{array}$ & 199 & 51.6 \\
\hline Religious taboo & 131 & 33.9 \\
\hline Insufficiency of legislation & 14 & 3.6 \\
\hline Awareness problem & 102 & 26.4 \\
\hline Insufficient vaccine & 128 & 33.2 \\
\hline Cultural constraints & 8 & 2.1 \\
\hline Large population of stray dogs & 230 & 59.6 \\
\hline $\begin{array}{l}\text { Insufficient habit of vaccinating } \\
\text { dogs or cats }\end{array}$ & 214 & 55.4 \\
\hline $\begin{array}{c}\text { Rabies was non-curable after the } \\
\text { onset of symptoms }\end{array}$ & 201 & 52.1 \\
\hline
\end{tabular}

Table 4: Target interviewee response for their respective attitude against rabies, 2016.

\begin{tabular}{|c|c|c|}
\hline Variables & Number of respondents & Percentage (\%) \\
\hline \multicolumn{2}{|c|}{ Immediate action after exposure to pet or rabid animal bite? } \\
\hline Nothing & 134 & 34.7 \\
\hline Washing wound & 1 & 0.3 \\
\hline $\begin{array}{c}\text { Consulting traditional } \\
\text { healer }\end{array}$ & 182 & 47.2 \\
\hline Medical management & 328 & 84.9 \\
\hline Confining dog & 134 & 34.7 \\
\hline Killing dog & 132 & 34.2 \\
\hline Other & 164 & 42.5 \\
\hline
\end{tabular}

Table 5: Practice of the respondents on rabies in and around Ambo Town, 2016.

(33.9\%), insufficient vaccine (33.2\%) and awareness problem $(26.4 \%)$ were responded by majority of the respondent in order of their level (degree) of constraint on the rabies prevention and control (Table 4).

Among the total respondents on immediate action after exposure to bite by rabid animal; nearly half (47.2\%) of the respondents used to consult traditional healers while $0.3 \%$ of them used to wash wound after bitten by rabid animals. However, $84.9 \%$ of the interviewed respondents actively sought medical management after bitten by rabid animal (Table 5).

\section{KAP score and associated factors}

Overall $53.9 \%, 50.5 \%$ and $63.5 \%$ of the participants had poor knowledge, good attitude and good practices, respectively (Table 6). Educational status significantly contributed to the level of knowledge. Accordingly, illiterates were 9.30 times more likely to have poor knowledge than those attended higher education [OR, 95\% CI: 9.30 (3.5,24.78), $\mathrm{P}<0.001]$. Similarly, educational status significantly affected attitudes of the respondents, but no significant factor affected the level of practices (Tables 6 and 7).

\section{Discussion}

This retrospective study indicated that the majority of the exposed populations were from Ambo town (54.3). Of total exposed individuals, majority (52.4\%) were males, which were due to bites especially either by domestic or stray dog $(94.2 \%)$ which led them PEP treatment. This is consistent with the study done in Jimma Town [9]. Additionally, a study by Kabeta et al. [10], indicated that significant proportion of the interviewed households (97.2\%) suggested rabies is transmitted to humans when they are bitten, scratched or licked by rabid dogs, cats and other animals. Another study by Kitalaa et al. [11] also reported that $97 \%$ of humans used post exposure treatments were due to dogs' bite in Kenya. 
Citation: Dabuma T, Kabeta T, Mengist HM (2017) Assessment of Basic Knowledge, Attitude and Practice of Community on Rabies and Retrospective Survey in and around Ambo Town, West Shoa Zone of Ethiopia. J Med Microb Diagn 6: 263. doi:10.4172/2161-0703.1000263

Page 4 of 5

\begin{tabular}{|c|c|c|c|}
\hline \multicolumn{4}{|c|}{ Variables } \\
\hline Knowledge & Score & Frequency & Percentage (\%) \\
\hline Greater than mean & Good & 178 & 46.1 \\
\hline Less than mean & Poor & 208 & 53.9 \\
\hline \multicolumn{4}{|c|}{ Attitude } \\
\hline Greater than mean & Good & 195 & 50.5 \\
\hline Less than mean & Poor & 191 & 49.5 \\
\hline \multicolumn{4}{|c|}{ Practice } \\
\hline Greater than mean & Good & 245 & 63.5 \\
\hline Less than mean & Poor & 141 & 36.5 \\
\hline
\end{tabular}

Table 6: Frequency of respondents according to KAP levels on rabies in and around Ambo town, 2016.

\begin{tabular}{|c|c|c|c|c|c|c|c|c|c|c|c|c|}
\hline \multirow[b]{2}{*}{ Variables } & \multicolumn{2}{|c|}{ Knowledge score } & \multirow[b]{2}{*}{ P-value } & \multirow[b]{2}{*}{ OR (95\%Cl) } & \multicolumn{2}{|c|}{ Attitude score } & \multirow[b]{2}{*}{$P$-value } & \multirow[b]{2}{*}{ OR $(95 \% \mathrm{Cl})$} & \multicolumn{2}{|c|}{ Practice score } & \multirow[b]{2}{*}{ P-value } & \multirow{2}{*}{$\begin{array}{c}\text { OR }(95 \% \\
\text { CI) }\end{array}$} \\
\hline & $\begin{array}{c}\text { Poor } \mathbf{n} \\
(\%)\end{array}$ & Good n (\%) & & & Poor n (\%) & $\begin{array}{c}\text { Good n } \\
(\%)\end{array}$ & & & $\begin{array}{c}\text { Poor } n \\
\text { (\%) }\end{array}$ & $\begin{array}{c}\text { Good n } \\
(\%)\end{array}$ & & \\
\hline \multicolumn{13}{|c|}{ Sex } \\
\hline Male & $98(25.4)$ & $85(22)$ & 0.9 & $\begin{array}{c}0.975(0.65- \\
1.45)\end{array}$ & $92(23.8)$ & $91(23.6)$ & 0.77 & $\begin{array}{c}1.06(0.71- \\
1.60)\end{array}$ & 69 (17.9) & $114(29.5)$ & 0.65 & $\begin{array}{c}1.10(0.73- \\
1.67)\end{array}$ \\
\hline Female & $\begin{array}{c}110 \\
(28.5)\end{array}$ & $93(24.1)$ & & 1 & $99(25.6)$ & $104(26.9)$ & & 1 & $72(18.7)$ & $131(33.9)$ & & 1 \\
\hline \multicolumn{13}{|c|}{ Age } \\
\hline $15-30$ & $73(19)$ & $49(12.7)$ & 0.43 & $\begin{array}{c}1.241(0.726- \\
2.122)\end{array}$ & $57(14.8)$ & $65(16.8)$ & 0.39 & $\begin{array}{c}0.79(0.47- \\
1.35)\end{array}$ & $38(9.8)$ & $84(21.8)$ & 0.15 & $\begin{array}{c}0.67(0.38- \\
1.16)\end{array}$ \\
\hline $31-50$ & $81(21)$ & $84(21.8)$ & 0.39 & $\begin{array}{c}0.804(0.488- \\
1.324)\end{array}$ & $82(21.2)$ & $83(21.5)$ & 0.66 & $\begin{array}{c}0.89(0.54- \\
1.50)\end{array}$ & $63(16.3)$ & $102(26.4)$ & 0.72 & $\begin{array}{c}0.91(0.55- \\
1.52)\end{array}$ \\
\hline$>50$ & $54(14)$ & $45(11.7)$ & - & 1 & $52(13.5)$ & $47(12.2)$ & - & 1 & $40(10.4)$ & $59(15.3)$ & - & 1 \\
\hline \multicolumn{13}{|c|}{ Education } \\
\hline Illiterate & $24(6.2)$ & $7(1.8)$ & $<0.001$ & $\begin{array}{c}9.30(3.50- \\
24.78)\end{array}$ & $14(3.6)$ & $17(4.4)$ & 0.12 & $\begin{array}{c}0.52(.22- \\
1.20)\end{array}$ & $12(3.1)$ & $19(4.9)$ & 0.6 & $\begin{array}{c}1.26(0.53- \\
2.99)\end{array}$ \\
\hline Informal & $60(15.5)$ & $40(10.4)$ & $<0.001$ & $\begin{array}{l}4.07(2.15- \\
7.73)\end{array}$ & $55(14.2)$ & $45(11.7)$ & 0.38 & $\begin{array}{c}0.76(0.42- \\
1.40)\end{array}$ & $32(8.3)$ & $68(17.6)$ & 0.65 & $\begin{array}{c}0.94(0.50- \\
1.77)\end{array}$ \\
\hline Primary & $63(16.3)$ & $34(8.8)$ & $<0.001$ & $\begin{array}{c}5.03(2.62- \\
9.65)\end{array}$ & $41(10.6)$ & $56(14.5)$ & 0.01 & $\begin{array}{c}0.46(0.25- \\
0.84)\end{array}$ & $36(9.3)$ & $61(15.8)$ & 0.6 & $\begin{array}{c}1.18(0.63- \\
2.20)\end{array}$ \\
\hline High school & $40(10.4)$ & $40(10.4)$ & $<0.001$ & $\begin{array}{c}2.71(1.40- \\
5.30)\end{array}$ & $33(8.5)$ & $47(12.2)$ & 0.01 & $\begin{array}{c}0.44(0.23- \\
.83)\end{array}$ & $35(9.1)$ & $45(11.7)$ & 0.73 & $\begin{array}{c}1.56(0.82- \\
2.97)\end{array}$ \\
\hline $\begin{array}{l}\text { Higher } \\
\text { education }\end{array}$ & $21(5.4)$ & $57(14.8)$ & - & 1 & $48(12.4)$ & $30(7.8)$ & - & 1 & $26(6.7)$ & $52(13.5)$ & - & 1 \\
\hline
\end{tabular}

Table 7: Association of socio-demographic factors KAP of respondents on rabies in and around ambo Town, 2016.

In this study children suffered animals' bite more. This is in agreement with a study by Deressa et al. [12] which reported that the most fatal cases (42\%) were from the age group 0-14 category and the least $(15.54 \%)$ were recorded in 50 years and above age category. The WHO data reported that most (30\% to $50 \%)$ of the victims of rabies reported from Africa and Asia were children [13].

Even though human-to-human transmission is extremely rare human rabies suspected cases were happened due to the human bite in present study which was $3.8 \%$. Similar findings were reported by different studies $[9,14]$. Additionally, this result is in line with another study from Ethiopia [15] that reported possible human-to-human transmission of rabies in Ethiopia.

In this study, the KAP survey was conducted on the community by face to face interview. The result indicated that $53.9 \%, 50.5 \%$ and $63.5 \%$ had poor knowledge, good attitude and acceptable practices on different variables related to rabies. In contrast to this finding higher knowledge, more positive attitudes and higher scores in practice indicators regarding rabies was reported from Sri Lanka [16]. This difference might be probably due to the absence of rabies related community health teaching extension services and formal mass Medias by cooperation of government, medical and veterinary professionals in and around Ambo as it was indicated by the respondents such as awareness problem (26.4\%) and insufficiency of responsible veterinarians $(51.6 \%)$. This poor knowledge level coincides with the insufficient level of knowledge about rabies dangers and prevention, particularly wound management and prompt PEP following exposure that was reported from Tanzania [17].

Some of the interviewees believed that rabies is caused by starvation; thirst and prolonged exposure to coldness and $30.6 \%$ of the respondents didn't know the cause of Rabies. About $29.8 \%$ of the respondents misunderstand that Rabies can spread from animal to human, animal to animal by utilizing the rabid animal flesh (the soft tissue of the body, especially muscle and fat) for food. Most the respondents especially the elders declare that if the animal died of the Rabies has been properly slaughtered and the carcass of that animal has been burned and inhaled it serves as one mechanism to cure animal infected of the disease.

In this study there was statistically significant association between educational level and knowledge scores of target respondents $(\mathrm{P}<0.0001)$ and there was no significant association between sex and age with knowledge scores $(\mathrm{P}>0.05)$. The respondents that have completed higher education has the highest knowledge scores (14.8\%) as compared the one who was unable to read and write has the lowest scores $(1.8 \%)$, attained primary $(8.8 \%)$ and informal school $(10.4 \%)$ which was similar with the findings of a study from Ethiopia [18]. This result is also supported by the result of the studies conducted in Flagstaff on community survey after rabies outbreaks in USA [19]. 
Citation: Dabuma T, Kabeta T, Mengist HM (2017) Assessment of Basic Knowledge, Attitude and Practice of Community on Rabies and Retrospective Survey in and around Ambo Town, West Shoa Zone of Ethiopia. J Med Microb Diagn 6: 263. doi:10.4172/2161-0703.1000263

There was no statistically significant association between sex and age with their attitude scores which implies that there was no as such difference in rabies exposures attitude between male and female and among different age groups. In converse of the current findings a study by Andrea and Jesse [18] showed statistically significant association between age and attitude scores that might be caused by the different attitude in time, humans individual perceptions, study area, voluntariness (willingness) of the respondents and the ability of the interviewer to attract the attention of the participants by using different tactics. However, there was significant association between educational level and attitude $(\mathrm{P}=0.04)$ that was in line of agreement with the same author $(\mathrm{p}<0.05)$.

No statistically significant association have been acquired during the current study between age $(\mathrm{p}=0.31)$ and practice scores which indicates there was no as such exaggerated knowledge variation between different age groups of respondents $(15-30,31-50,>50)$ that was consistent with the finding of Abraham et al $(p=0.366)$ [18]. The current study KAP analysis indicated that the average good KAP score of the community was about $53.4 \%$ that was lower than the previous data [19], that indicated about $64.1 \%$ of the respondents had good level of knowledge, attitude and practices about rabies that might be due absence of community awareness of the disease in the current finding.

About $54.3 \%$ of the exposed patient came from different rural areas surrounding Ambo town during the study period that might be because of many districts and inappropriate delivery of medical prophylaxis in their health centre or lack of health centre that carries out this rabies exposure management. As confirmed from the interview of exposed humans the highest incidence of bites has been occurred during autumn and winter (that strongly agrees with the study conducted by the author [9], (35.4\%) which was $35.6 \%$ unlike the community survey of rabies basic knowledge.

\section{Conclusion}

The current health centre based retrospective study indicated that the majority of humans suspected of rabies cases were males and children's that was most frequently caused by dog bites that occurred during Winter and autumn. The assessment of KAP of community in and around Ambo indicate that about 53.4\% of the respondents have good level of KAP scores despite the poor knowledge (53.9\%) of rabies and its suspected exposures management such as PEP. Most of the respondents have misunderstanding on the cause and modes of transmission of rabies. In this study education has statistically significant association with knowledge and attitude scores. Community knowledge such as the cause, means of transmission, prevention mechanisms by pets and humans vaccination and management of rabies exposures by PEP in health centre rather than to rely on herbal remedies should be raised through designing urgent periodic education,

\section{Competing Interests}

All authors declare that they have no conflict of interest associated with the publication of this manuscript.

\section{Authors' Contributions}

Conceived and designed the experiments: TD. Performed the experiments: TD. Analyzed the data: TD. Contributed reagents/materials/analysis tools: TD Wrote the paper: TD. Assisted with design, analysis, and interpretation of data:
TK, HMM. Critical review of the manuscript: TK, HMM. Read and approved the final manuscript: TD, TK, HMM. Critical appraisal of the manuscript: TD, TK, HMM

\section{Acknowledgements}

This study was funded by Wollega University, Ethiopia. We would like to thank the Wollega University for financial and administrative support, all study participants for their cooperation, for those who supported to carry out this study.

\section{References}

1. World Health Organization (WHO) (2002) Future trends in veterinary public health, Report of the WHO study group. WHO Technical Report Series 907. World Health Organization, Geneva, Switzerland.

2. Kobayashi Y, Ogawa A, Sato G, Sato T, Itou T, et al. (2006) Geographical distribution of vampire bat-related bovine rabies in Brazil. J Vet Med Sci 68: 1097-1100.

3. Krauss HA, Weber M, Appel B, Enders HD, Isenbers HG, et al (2003) Zoonoses. American Society for Microbiology. pp. 113-118.

4. Eshetu Y, Arthuro M, Mekoro B, Abebe B, Girum T, et al (2012) Study on knowledge, attitude and dog ownership patterns related to rabies prevention and control in Addis Ababa, Ethiopia. Ethiop Vet J 17: 27-39.

5. Girma T, Yimer E, Geyid A (2002) Endemic existence of rabies in Ethiopia Ethiop Med J 40: 163-170.

6. Central Statistics Agency (CSA) (2007) Summary and statistical report of the population and housing census, Addis Ababa, Ethiopia. p. 114.

7. Lemma M, KassaT, Tegegne A (2001) Clinically manifested major health problems of crossbred dairy herds in urban and peri-urban production in the high lands of Ethiopia. Trop Anim Health Prod 33:85-93.

8. Thursfield M (2005) Survey in veterinary. Epidemiology. (2nd edn), Blackwell Science, Limited, Cambridge, UK. p. 297-302.

9. Kabeta T, Tigre W, Deressa D (2014) Occurrence of suspected rabies cases in humans Jimma Zone and surrounding areas, South West Ethiopia. Intl J Basic Appl Virol 3: 28-34.

10. Ali A, Ahmed EY, Sifer D (2013) A study on knowledge, attitude and practice of rabies among residents in Addis Ababa, Ethiopia. Ethiop Vet J 17: 19-35.

11. Kitalaa PM, McDermotta JJ, Kyulea MN, Gathumaa JM (2000) Community based active surveillance for rabies in Machakos District, Kenya. Prev Vet Med 44: 73-85

12. Deressa A, Ali A, Mekoro B, Bethelehem N, Yimer E, et al. (2010) The status of rabies in Ethiopia: A retrospective records reviews. J Health Dev 24: 127-132.

13. World Health Organization (WHO) (2005) WHO expert consultation on rabies World Health Organ Tech Rep Ser 93: 1-88.

14. Carter JB, Saunders VA (2007) Virology: Principles and applications. John Wiley and Sons Ltd, England, UK. p. 175-184.

15. Fekadu M, Endeshaw T, Alemu W, Bogale Y, Teshager T, et al. (1996) Possible human-to-human transmission of rabies in Ethiopia. Ethiop Med J 34: 123-127.

16. Gino C, Yoshihide O, Koji K, Hiroko Y, Bandula R, et al. (2009) A pilot study on the usefulness of information and education campaign materials in enhancing the knowledge, attitude and practice on rabies in rural Sri Lanka. J Infect Dev Ctries 3: 55-64.

17. Sambo MB (2012) Epidemiological dynamics of rabies in Tanzania and its impacts on local communities. 51.

18. Andrea M, Jesse D (2012) Community survey after rabies outbreaks, Flagstaff, Arizona, USA. Emerg Infect Dis 18: 6-12.

19. Guadu T, Shite A, Chanie M, Bogale B, Fentahun T (2014) Assessment of knowledge, attitude and practices about rabies and associated factors: In the case of Bahir Dar Town. Global Veterinaria 13: 348-35. 